\begin{tabular}{l|l} 
Postprint Version & 1.0 \\
Journal website & http://lysander.ingentaselect.com \\
Pubmed link & $\begin{array}{l}\text { http://www.ncbi.nlm.nih.gov/entrez/query.fcgi?cmd=Retrieve\&db=pubmed\&dop } \\
\text { t=Abstract\&list uids=12745948\&query hl=22\&itool=pubmed docsum }\end{array}$ \\
\hline DOI & $\underline{10.1080 / 0963828021000058530}$
\end{tabular}

\title{
The possession of technical aids among persons with a somatic chronic disease
}

\author{
J. DEKKER ${ }^{\dagger *}$, M. RIJKEN ${ }^{\ddagger}$, M. VAN POPPEL ${ }^{\S}$ AND A. DE BRUIN ${ }^{\Uparrow}$ \\ † Department of Rehabilitation Medicine, VU University Medical Centre, PO Box 7057, 1007 MB, \\ Amsterdam, The Netherlands \\ * Author for correspondence; e-mail: j.dekker@vumc.nl \\ $\ddagger$ Netherlands Institute of Health Services Research, Utrecht, The Netherlands \\ $\S$ Institute for Extramural Research, VU University Medical Center, Amsterdam, The Netherlands \\ II Rehabilitation Centre 'Rijndam Adriaan Stichting', Rotterdam, The Netherlands
}

\begin{abstract}
Purpose: Previous research has highlighted disability as a determinant of the need for technical aids; surprisingly, disease as a potential determinant has been ignored. The goal of the present study was to determine whether the possession of technical aids is dependent on the type of chronic disease, illness duration, co-morbidity, disability, age, and several other factors.
\end{abstract}

Methods: The study was performed in a representative sample of persons with a somatic chronic disease $(\mathrm{n}=2262)$. Type of chronic disease, time post-diagnosis and co-morbidity were assessed by the patient's general practitioner. Disability was assessed with the Sickness Impact Profile. The possession of technical aids and other characteristics were assessed by questionnaire.

Results: Type of chronic disease (osteoarthritis, rheumatoid arthritis, diabetes and COPD), disability, age and gender were significantly and independently associated with the possession of technical aids.

Conclusions: Apart from disability, disease-, age-, and genderrelated characteristics determine the possession of technical aids. A detailed assessment of these characteristics is required in order to ensure that technical aids meet personal needs.

\section{INTRODUCTION}

Disability has been shown to be a strong determinant of the need for technical aids: disabled persons frequently possess technical aids. ${ }^{1-5}$ In addition, a high number of chronic conditions and poor selfreported health are associated with the possession of technical aids. ${ }^{2,3,5}$ Increased age, a high educational level, an average income (as contrasted to a low or high income) and rural residency are also associated with the possession of technical aids. ${ }^{1-5}$ Concerning gender, conflicting findings have been reported. ${ }^{1-3}$

Previous research has highlighted disability as a determinant of need for technical aids. Surprisingly, disease as a potential determinant of the need for technical aids has been ignored. Disease and diseaserelated factors other than disability could be important determinants of the need for technical aids. For example, in patients with rheumatoid arthritis impairments of the foot (e.g. pain) might be important determinants of the need for orthopaedic footwear. Similarly, the duration of illness and the number of 
co-morbid conditions may be expected to influence the need for technical aids. Therefore, it seems worthwhile to study whether disease is a determinant of the need for technical aids. A descriptive study on the relationship between disease, disease related-characteristics and the possession of technical aids is a first step towards the understanding of disease as a determinant of the need for technical aids.

Thus, the aim of the present study was to determine whether the possession of technical aids is dependent on the type of (chronic) disease, illness duration, comorbidity, disability, age, and several other factors.

\section{METHOD}

\section{SAMPLE}

The sample consists of 2262 patients with a variety of somatic chronic diseases. All subjects participated in the 'Panel of Patients with Chronic Diseases' (PPCD). PPCD is a longitudinal research programme on the consequences of chronic disease for the quality of life (QOL), use of health care and social participation of patients. ${ }^{6}$

At the end of 1997, patients were recruited via 56 randomly selected general practices in the Netherlands. General practitioners selected patients from their files according to the following criteria: a diagnosis of a non-curable or generally long-lasting disease by a certified medical practitioner, being aged 15 years or older, being non-institutionalized, being aware of diagnosis, not being terminally ill, being mentally and physically able to participate, and having sufficient mastery of the Dutch language. The level of disability was not a selection criterion. Based on these criteria, the general practitioners selected 5.810 patients from their files: 3.301 (i.e. $57 \%$ ) of these patients agreed to participate in the Panel. Patients were sent a questionnaire twice a year. For the purpose of the present study, only patients that had filled in both questionnaires of 1998 were included $(n=2262)$. Details of the sample are described in the Results section.

\section{MEASURING INSTRUMENTS}

\section{Type of chronic disease, time post-diagnosis, and co-morbidity}

Patients were classified by their general practitioner in terms of their diagnosis using the International Classification of Primary Care. ${ }^{7}$ Patients with more than one disease meeting the selection criteria were classified on the base of the oldest diagnosis (index disease). Next, the index diseases were divided into ten categories: ischaemic heart disease, COPD, asthma, osteoarthritis, rheumatoid arthritis, cancer, diabetes mellitus, progressive neurological diseases, digestive diseases, and other. The time post-diagnosis was operationalized as the number of years that had passed since diagnosis of the index disease (as registered by the general practitioner). Other chronic diseases registered by the general practitioner were considered as co-morbidity. In this study, co-morbidity was defined as the presence of another chronic disease in addition to the index disease. ${ }^{8}$

\section{Disability}

Three subscales of a shortened version of the Sickness Impact Profile (SIP68) ${ }^{9,10}$ were used as measures of disability: somatic autonomy (17 items), mobility control (12 items), and psychic autonomy and communication (11 items). Somatic autonomy describes the degree to which an individual is autonomous in basic somatic functioning. Functions referred to are bathing, getting dressed, feeding, maintaining balance, rising, getting around in a wheelchair, getting in and out of bed, toilet use and incontinence. Mobility control is related to the degree to which an individual has control over his body. Six out of the 12 items of this subscale directly refer to walking; the other items refer to kneeling, stooping or bending down, getting in and out of bed, standing, getting dressed, moving hands and fingers, and using hands. Psychic autonomy and communication describes the level to which an individual is able to operate without help of others in mental areas of functioning, including the possible impact on a person's (verbal) ability to communicate. Items are concerned with reasoning, solving problems, concentrating, responding, remembering, speaking, and writing or typing ability. Since the scores obtained on the three measures were skewed, we decided to dichotomize these variables: 0 (no disability at all) and 1 (at least one disability). 


\section{Other characteristics: age, gender, marital status, and type of health care insurance}

Marital status was dichotomized in married/cohabiting versus not married/cohabiting, because of the small number of patients who were living alone, divorced or widowed. Type of health care insurance was divided into two categories: public insurance versus private insurance.

\section{Technical aids}

In the questionnaire 14 technical aids for disabled persons were addressed, i.e. aids for personal care, (urine) absorbing aids, aids for housekeeping, orthoses and prostheses, walking aids, orthopaedic footwear, anti-oedema stockings, wheelchairs, car adaptations, furnishings, adaptations to homes, hearing-aids, aids for dosing medicines and injection materials, and alarm systems (see table 1 for ISO-codes) ${ }^{11}$ Patients were asked whether they possessed the technical aids mentioned above.

\section{[ TABLE 1 ]}

\section{ANALYSIS}

The numbers and percentages of chronically ill patients possessing the 14 technical aids were assessed. Technical aids that were possessed by more than 100 patients were analysed further. In a multivariate analysis, logistic regression analyses were performed with the selected technical aids as dependent variables. Type of chronic disease, disability and other characteristics were entered together, and odds ratios with 99\%-confidence intervals for these variables were computed.

\section{RESULTS}

\section{CHARACTERISTICS OF THE SAMPLE}

Frequently occurring diseases in the sample are diabetes mellitus, asthma, COPD and osteoarthritis (see table 1). Patients with progressive neurological diseases (multiple sclerosis or Parkinson's disease) and digestive diseases are the smallest diagnostic groups in this sample. Patients suffering from a chronic disease occurring relatively seldom (in less than $2 \%$ of the sample) were categorized in the 'other' category. The mean time post-diagnosis is 10 years. The table shows that about a quarter of the patients has a co-morbid condition. Disabilities in mobility control occur most often; almost half of the patients (46\%) report one or more problems regarding mobility. One quarter of the patients (24\%) report having problems to maintain psychic autonomy and communication. Disabilities in somatic autonomy are reported by 15 per cent of the patients. Table 2 also describes the socio-demographic characteristics of the sample.

\section{[ TABLE 2 ]}

\section{TECHNICAL AIDS}

Table 1 gives insight into the possession of technical aids by chronically ill patients. The possession of technical aids among the chronically ill ranges from 2.5 per cent to 9.9 per cent. (One should note that visual aids, which are probably used very often, were not included in this study.) Walking aids are most often reported; 10 per cent of the patients possess these aids. Other more frequently reported technical aids are adaptations to homes, aids for dosing medicines/injections materials, and antioedema stockings.

\section{PREDICTORS OF THE POSSESSION OF TECHNICAL AIDS}

The results of the analysis are presented in table 3 . When taking all other variables into account, type of chronic disease is a significant predictor of the possession of six out of nine technical aids analysed. Rheumatoid arthritis is a predictor of the possession of aids for personal care, orthopaedic footwear, furnishings and adaptations to homes. Osteoarthritis is a significant predictor of the possession of walking aids and furnishings. Diabetes and COPD are predictors of the possession of aids for dosing medicines. 


\section{[ TABLE 3 ]}

With regard to other disease-related characteristics, time post-diagnosis and co-morbidity are not significant predictors of the possession of technical aids, with one exception: in patients with comorbidity, the possession of aids for dosing medicines is almost twice as high as in patients with only one chronic disease.

Disability is significantly related to the possession of most technical aids. This applies to disability in somatic autonomy and mobility control, which are predictors of the possession of aids for personal care, urine absorbing aids (somatic autonomy only), walking aids, orthopaedic footwear, anti-oedema stockings, furnishings, and adaptation to homes. Disability in psychic autonomy and communication was not related to any of the technical aids.

When taking all other variables into account, age is a significant predictor of the use of (urine) absorbing aids, walking aids, anti-oedema stockings, hearing-aids and aids for dosing medicines. The possession of these technical aids significantly increases with age with the exception of the aids for dosing medicines, which appears to decrease with age. Gender is also a significant predictor of the possession of (urine) absorbing aids, walking aids and anti-oedema stockings. These aids are more often used by female patients. In general, marital status and type of health care insurance are not related to the possession of technical aids. However, the possession of aids for dosing medicines appears to be more common among patients with a private insurance.

\section{DISCUSSION}

A considerable number of patients with a somatic chronic disease possess a technical aid: the percentage of patients possessing a technical aid varies from 2.5 (aids for housekeeping) to 9.9 (walking aids). Disability was found to be a strong predictor of the possession of technical aids. Our findings in this respect are similar to those of others, ${ }^{1-5}$ who also showed that disability is a strong predictor of the possession of technical aids. However, after controlling for the level of disability, type of disease remains a strong predictor of the possession of technical aids. This applies in particular to osteoarthritis, rheumatoid arthritis, COPD and diabetes. Thus, characteristics of these diseases other than disability appear to determine the possession of technical aids. In the case of diabetes, impaired glucose tolerance (an impairment rather than a disability) explains the possession of aids for dosing medicine (injection materials). With regard to COPD, the degree of airway obstruction (an impairment rather than a disability) probably determines the possession of aids for dosing medicine (inhalators). In the case of osteoarthritis and rheumatoid arthritis, impairments (e.g. instability of joints, pain) associated with the disease could explain the possession of aids for personal care, walking aids and orthopaedic footwear. Similarly handicaps (e.g. difficulties in doing the housekeeping) associated with osteoarthritis and rheumatoid arthritis explain the possession of furnishings and adaptations to homes. Increased age and gender (women) are significant predictors of the possession of technical aids. The effect of age is very strong: the odds ratio's reported in table 3 apply to an increase in age of 1 year, which means that the possession of aids depends to a very large extent on age. Apparently, age-related characteristics (not being type of disease, co-morbidity, illness duration or disability) exert a strong influence. Again, one might argue that age-related impairments offer an explanation. In a recent review Pape et al. ${ }^{12}$ concluded that older adults use assistive devices to diminish the effects of illnesses and the physiological and cognitive changes due to ageing. Thus, our study and the review of Pape et al. point to the same conclusion: age-related impairments are a strong determinant of the need of technical aids. Pape et al. also concluded that duration of disease is a factor in the need of technical aids. In the multivariate analysis of our data, time post-diagnosis was not associated with the possession of technical aids: because age and time post-diagnosis are associated, and because age had such a strong effect in our multivariate analysis, it may not have been possible to demonstrate an independent effect of time post-diagnosis on the possession of technical aids. As regards gender, women were found to be more likely to possess (urine) absorbing aids and anti-oedema-stockings: these effects probably are also explained by the presence of physiological impairments. Thus, the findings on age and gender strongly suggest that impairments are an important determinant of the need for technical aids. This conclusion is in line with the view of Pape et al. 
Disability was found to be a powerful predictor of the possession of technical aids. Both restrictions in somatic autonomy (referring to restrictions in the performance of activities such as bathing, getting dressed and eating) and mobility control (referring to restrictions in activities such as walking and bending down) are associated with the possession of technical aids. The association between disability and the possession of technical aids confirms previous findings. ${ }^{1-5}$ Recently, Hammel et al. ${ }^{13}$

demonstrated a beneficial effect of using technical aids on the performance of functional tasks. Thus, disability is a strong determinant of the need of technical aids and technical aids help to overcome disability.

The present study leads to the conclusion that, apart from disability, the need of technical aids is determined by disease-, age- and gender-related characteristics. It is suggested that these characteristics related to disease, age and gender operate through impairments: impairments seem to determine the need for technical aids. A detailed assessment of these impairments, disability and other factors ${ }^{14,15}$ is required in order to ensure that technical aids meet personal needs.

\section{ACKNOWLEDGMENTS}

This study was supported by a grant from the Ministry of Health, the Inspectorate of Health Care and the National Council on Chronically Ill People.

\section{REFERENCES}

1 Edwards MI, Jones DE. Ownership and use of assistive devices amongst older people in the community. Age and Ageing 1998; 27: 463 - 468.

2 Hartke RJ, Prohaska TR, Furner SE. Older adults and assistive devices. Journal of Aging and Health 1998; 10: $99-116$.

3 de Klerk MMY, Huijsman R, McDonnell J. The use of technical aids by elderly in the Netherlands. Gerontologist 1997; 37: 365 - 373.

4 Verbrugge LM, Rennert C, Madars $\mathrm{JH}$. The great efficacy of personal and equipment assistance in reducing disability. American Journal of Public Health 1997; 87: $384-392$.

5 Zimmer Z, Chappell NL. Mobility restriction and the use of devices among seniors. Journal of Aging and Health 1994; 6: $185-208$.

6 Rijken PM, Foets M, Peters L, de Bruin AF, Dekker J. Patie"ntenpanel Chronisch ZiekenKerngegevens 1998. Utrecht: NIVEL, 1999.

7 Lamberts H, Wood. ICPC: International Classification of Primary Care. Oxford: Oxford University Press, 1987.

8 van den Akker M, Buntinx F, Knottnerus JA. Comorbidity or multimorbidity: What's in a name. A review of literature. European Journal of General Practice 1996; 2: $65-70$.

9 de Bruin AF, Buys M, de Witte LP, Diederiks JPM. The Sickness Impact Profile: SIP68, a short generic version. First evaluation of the reliability and reproducibility. Journal of Clinical Epidemiology 1994; 47: $863-871$.

10 Post MWM, de Bruin AF, de Witte LP, Schrijvers G. The SIP68: A measure of health-related functional status in rehabilitation medicine. Archives of Physical Medicine and Rehabilitation 1998; 79: $395-401$.

11 International Organization for Standardization. International standard. Technical Aids for Disabled Persons-Classification. ISO/FDIS 9999. Geneva: ISO, 1997.

12 Pape TLB, Kim J, Weiner B. The shaping of individual meanings assigned to assistive technology: a review of personal factors. Disability and Rehabilitation 2002; 24: $5-20$.

13 Hammel J, Lai JS, Heller T. The impact of assistive technology and environmental interventions on function and living situation status with people who are ageing with developmental disabilities. Disability and Rehabilitation 2002; 24: 93 - 105.

14 Scherer MJ. The change in emphasis from people to person: introduction to the special issue on assistive technology (editorial). Disability and Rehabilitation 2002; 24: 1-4.

15 Day H, Jutai J, Campbell KA. Development of a scale to measure the psychosocial impact of assistive devices: lessons learned and the road ahead. Disability and Rehabilitation 2002; 24: 31 37. 
Dekker, J., Rijken, M., Poppel, M. van, Bruin, A. de

The possession of technical aids among persons with a somatic chronic disease.

Disability and Rehabilitation: 25, 2003, nr. 8, p. 393-398

\section{TABLES}

Table 1 Numbers and percentages of chronically ill patients possessing technical aids $(N=2262)$

\begin{tabular}{llrl}
\hline Technical aids & ISO-codes & $n$ & $\%$ \\
\hline Aids for personal care & 09 (ex. -30$)$ & 138 & 6.1 \\
(Urine) absorbing aids & 36432 & 114 & 5 \\
Aids for housekeeping & 15 & 56 & 2.5 \\
Orthoses and prostheses & $06(\mathrm{ex} .-33)$ & 73 & 3.2 \\
Walking aids & $12-03,12-06$ & 223 & 9.9 \\
Orthopaedic footwear & $06-33$ & 145 & 6.4 \\
Anti-oedema stockings & 38870 & 160 & 7.1 \\
Wheelchairs & 36514 & 97 & 4.3 \\
Car adaptations & 36505 & 72 & 3.2 \\
Furnishings & $18-03,18-09,18-12,18-15$ & 106 & 4.7 \\
Adaptations to homes & $18(\mathrm{ex} .-03,-09,-12,-15)$ & 189 & 8.4 \\
Hearing-aids & $21-45$ & 150 & 6.6 \\
Aids for dosing medicines $/$ & $03-03,03-18,03-21$ & 186 & 8.2 \\
$\quad$ injection materials & $21-51$ & 79 & 3.5 \\
Alarm systems & & & \\
\hline
\end{tabular}

Table 2 Socio-demographic and disease-related characteristics of the sample $(N=2262)$

\begin{tabular}{|c|c|c|c|c|}
\hline & $N$ & $\%$ & Mean & $S D$ \\
\hline Age (in years) $(N=2241)$ & & & 56.8 & 16.3 \\
\hline \multicolumn{5}{|l|}{ Gender $(N=2242)$} \\
\hline male & 960 & 42.8 & & \\
\hline female & 1282 & 57.2 & & \\
\hline \multicolumn{5}{|l|}{ Marital status $(N=2237)$} \\
\hline married/cohabiting & 1651 & 73.8 & & \\
\hline single/divorced/widowed & 586 & 26.2 & & \\
\hline \multicolumn{5}{|l|}{ Health care insurance $(N=2229)$} \\
\hline public & 1467 & 65.8 & & \\
\hline private & 762 & 34.2 & & \\
\hline \multicolumn{5}{|l|}{ Index disease } \\
\hline ischemic heart diseases & 131 & 5.8 & & \\
\hline COPD & 197 & 8.7 & & \\
\hline asthma & 213 & 9.4 & & \\
\hline osteoarthritis & 167 & 7.4 & & \\
\hline rheumatoid arthritis & 113 & 5.0 & & \\
\hline cancer & 110 & 4.9 & & \\
\hline diabetes mellitus & 278 & 12.3 & & \\
\hline progressive neurological diseases & 45 & 2.0 & & \\
\hline digestive diseases & 58 & 2.6 & & \\
\hline other chronic diseases & 950 & 42.0 & & \\
\hline Time post-diagnosis (in years) & & & 10.0 & 9.1 \\
\hline \multicolumn{5}{|l|}{ Co-morbidity } \\
\hline absent & 1644 & 72.7 & & \\
\hline present & 618 & 27.3 & & \\
\hline \multicolumn{5}{|l|}{ Disability in: } \\
\hline \multicolumn{5}{|l|}{ Somatic autonomy $(N=2148)$} \\
\hline absent & 1873 & 85.5 & & \\
\hline present & 311 & 14.5 & & \\
\hline \multicolumn{5}{|l|}{ Mobility control $(N=2184)$} \\
\hline absent & 1173 & 53.7 & & \\
\hline present & 1011 & 46.3 & & \\
\hline \multicolumn{5}{|l|}{$\begin{array}{l}\text { Psychic autonomy and } \\
\text { communication }(N=2184)\end{array}$} \\
\hline absent & 1658 & 75.9 & & \\
\hline present & 526 & 24.1 & & \\
\hline
\end{tabular}


Dekker, J., Rijken, M., Poppel, M. van, Bruin, A. de

The possession of technical aids among persons with a somatic chronic disease.

Disability and Rehabilitation: 25, 2003, nr. 8, p. 393-398

Table 3 Logistic regression analyses with technical aids as dependent variables: odds ratios and 99\%-confidence intervals $(N=2104)$

\begin{tabular}{|c|c|c|c|}
\hline & $\begin{array}{l}\text { Aids for personal care } \\
\text { Odds }(99 \%-C I)\end{array}$ & $\begin{array}{l}\text { (Urine) absorbing aids } \\
\text { Odds }(99 \%-C I)\end{array}$ & $\begin{array}{c}\text { Walking aids } \\
\text { Odds }(99 \%-C I)\end{array}$ \\
\hline Age & $1.01(0.99-1.03)$ & $1.02(1.00-1.05)^{*}$ & $1.02(1.00-1.04)^{*}$ \\
\hline Male & $0.59(0.32-1.07)$ & $0.29(0.13-0.61)^{* *}$ & $0.55(0.34-0.91)^{*}$ \\
\hline Married/cohabiting & $0.95(0.53-1.69)$ & $0.94(0.50-1.77)$ & $0.86(0.53-1.39)$ \\
\hline Public insurance & $1.05(0.59-1.88)$ & $0.95(0.51-1.78)$ & $1.07(0.66-1.74)$ \\
\hline Time post-diagnosis & $1.37(0.54-3.51)$ & $0.67(0.19-2.39)$ & $0.81(0.33-1.96)$ \\
\hline Co-morbidity & $1.21(0.67-2.18)$ & $1.45(0.76-2.73)$ & $1.22(0.75-1.99)$ \\
\hline \multicolumn{4}{|l|}{ Index disease: } \\
\hline Ischemic heart diseases & $0.95(0.25-3.59)$ & $0.16(0.01-2.43)$ & $1.18(0.44-3.20)$ \\
\hline COPD & $0.96(0.35-2.69)$ & $1.40(0.52-3.74)$ & $0.50(0.19-1.30)$ \\
\hline Asthma & $0.65(0.16-2.66)$ & $1.37(0.45-4.17)$ & $0.71(0.25-2.07)$ \\
\hline Osteoarthritis & $1.72(0.77-3.84)$ & $0.69(0.24-1.96)$ & $2.27(1.19-4.34) *$ \\
\hline Rheumatoid arthritis & $4.18(1.85-9.44)^{* *}$ & $0.62(0.17-2.35)$ & $1.25(0.54-2.91)$ \\
\hline Cancer & $1.17(0.31-4.37)$ & $0.86(0.20-3.70)$ & $1.05(0.35-3.15)$ \\
\hline Diabetes mellitus & $0.99(0.40-2.49)$ & $0.72(0.26-1.94)$ & $0.79(0.37-1.71)$ \\
\hline Prog. neurological diseases & $1.19(0.27-5.33)$ & $3.33(0.95-11.62)$ & $1.33(0.41-4.29)$ \\
\hline Digestive diseases & $0.84(0.06-12.56)$ & $1.77(0.25-12.75)$ & $1.05(0.14-7.72)$ \\
\hline \multicolumn{4}{|l|}{ Disability in: } \\
\hline Somatic autonomy & $3.59(2.04-6.30)^{* * *}$ & $6.27(3.28-11.98)^{* * t}$ & $3.86(2.41-6.20)^{* \%}$ \\
\hline Mobility control & $5.68(2.41-13.41)^{* *}$ & $1.95(0.88-4.34)$ & $7.51(3.60-15.67)^{* *}$ \\
\hline \multirow[t]{2}{*}{ Psychic autonomy and communication } & $0.91(0.52-1.59)$ & $0.91(0.49-1.72)$ & $0.96(0.60-1.53)$ \\
\hline & $\begin{array}{l}\text { Orthopaedic footwear } \\
\text { Odds }(99 \%-C I)\end{array}$ & $\begin{array}{l}\text { Anti-oedema stockings } \\
\text { Odds }(99 \%-C I)\end{array}$ & $\begin{array}{c}\text { Furnishings } \\
\text { Odds }(99 \%-C I)\end{array}$ \\
\hline Age & $0.99(0.98-1.01)$ & $1.03(1.01-1.05)^{* * *}$ & $0.99(0.97-1.01)$ \\
\hline Male & $1.26(0.73-2.17)$ & $0.49(0.29-0.83)^{* * *}$ & $0.96(0.51-1.83)$ \\
\hline Married/cohabiting & $0.89(0.49-1.46)$ & $1.04(0.62-1.76)$ & $0.88(0.46-1.69)$ \\
\hline Public insurance & $0.84(0.49-1.46)$ & $0.84(0.52-1.38)$ & $0.95(0.49-1.81)$ \\
\hline Time post-diagnosis & $0.66(0.17-2.56)$ & $0.42(0.12-1.44)$ & $0.96(0.26-3.52)$ \\
\hline Co-morbidity & $1.10(0.61-1.97)$ & $1.16(0.69-1.94)$ & $1.23(0.62-2.44)$ \\
\hline \multicolumn{4}{|l|}{ Index disease: } \\
\hline Ischemic heart diseases & $1.48(0.50-4.42)$ & $1.03(0.39-2.72)$ & $\$$ \\
\hline COPD & $0.26(0.05-1.28)$ & $0.64(0.26-1.57)$ & $0.24(0.04-1.67)$ \\
\hline Asthma & $0.65(0.18-2.32)$ & $1.19(0.51-2.78)$ & $0.36(0.05-2.46)$ \\
\hline Osteoarthritis & $1.68(0.74-3.80)$ & $0.76(0.34-1.72)$ & $2.59(1.13-5.93)^{*}$ \\
\hline Rheumatoid arthritis & $6.30(3.03-13.13)^{* *}$ & $0.59(0.20-1.77)$ & $2.75(1.08-6.99)^{*}$ \\
\hline Cancer & $0.42(0.06-2.81)$ & $0.80(0.27-2.40)$ & $1.25(0.29-5.37)$ \\
\hline Diabetes mellitus & $1.08(0.45-2.59)$ & $0.45(0.19-1.09)$ & $0.98(0.35-2.76)$ \\
\hline Prog. neurological diseases & $0.39(0.06-2.79)$ & $0.64(0.12-3.26)$ & $2.78(0.82-9.40)$ \\
\hline Digestive diseases & $2.10(0.41-10.83)$ & $0.37(0.03-5.15)$ & $1.05(0.07-15.90)$ \\
\hline \multicolumn{4}{|l|}{ Disability in: } \\
\hline Somatic autonomy & $3.20(1.78-5.74)^{* *}$ & $2.02(1.15-3.54)^{*}$ & $4.98(2.64-9.39)^{* * *}$ \\
\hline Mobility control & $3.35(1.68-6.69)^{* * t}$ & $1.84(1.04-3.26)^{*}$ & $5.68(2.08-15.52)^{* *}$ \\
\hline \multirow[t]{3}{*}{ Psychic autonomy and communication } & $1.48(0.86-2.55)$ & $0.92(0.53-1.58)$ & $1.16(0.63-2.14)$ \\
\hline & Adaptations to homes & Hearing-aids & Aids for dosing medicines \\
\hline & Odds $(99 \%-C I)$ & Odds $(99 \%-C I)$ & Odds $(99 \%-C I)$ \\
\hline Age & $1.00(0.98-1.01)$ & $1.07(1.05-1.10)^{* * *}$ & $0.97(0.95-0.98)^{* * *}$ \\
\hline Male & $0.77(0.47-1.28)$ & $0.88(0.52-1.50)$ & $1.01(0.61-1.68)$ \\
\hline Married/cohabiting & $0.91(0.55-1.50)$ & $0.88(0.51-1.52)$ & $1.50(0.82-2.74)$ \\
\hline Public insurance & $1.42(0.84-2.40)$ & $1.14(0.67-1.93)$ & $0.58(0.35-0.97)^{*}$ \\
\hline Time post-diagnosis & $1.09(0.43-2.75)$ & $0.63(0.22-1.84)$ & $1.88(0.62-5.74)$ \\
\hline Co-morbidity & $1.32(0.79-2.21)$ & $1.00(0.58-1.71)$ & $1.96(1.10-3.47)^{*}$ \\
\hline \multicolumn{4}{|l|}{ Index disease: } \\
\hline Ischemic heart diseases & $0.58(0.16-2.14)$ & $0.81(0.31-2.15)$ & $0.42(0.03-6.02)$ \\
\hline COPD & $0.95(0.40-2.24)$ & $0.60(0.25-1.46)$ & $3.18(1.17-8.61)^{*}$ \\
\hline Asthma & $1.20(0.48-2.99)$ & $0.94(0.33-2.69)$ & $1.58(0.55-4.57)$ \\
\hline Osteoarthritis & $1.11(0.51-2.38)$ & $0.42(0.15-1.12)$ & $1.01(0.20-5.11)$ \\
\hline Rheumatoid arthritis & $2.24(1.02-4.92)^{*}$ & $0.63(0.19-2.07)$ & $1.56(0.37-6.63)$ \\
\hline Cancer & $0.70(0.19-2.59)$ & $0.53(0.15-1.89)$ & $0.89(0.13-6.12)$ \\
\hline Diabetes mellitus & $0.87(0.39-1.93)$ & $0.74(0.34-1.61)$ & $46.59(23.27-93.25)^{* \%}$ \\
\hline Prog. neurological diseases & $2.39(0.80-7.10)$ & $1.34(0.33-5.34)$ & $2.00(0.27-14.62)$ \\
\hline Digestive diseases & $\$ \$$ & $0.50(0.03-7.09)$ & $0.69(0.059-9.97)$ \\
\hline \multicolumn{4}{|l|}{ Disability in: } \\
\hline Somatic autonomy & $5.29(3.23-8.66)^{* *}$ & $1.68(0.93-3.03)$ & $1.96(0.91-4.22)$ \\
\hline Mobility control & $5.25(2.62-10.52)^{* *}$ & $1.42(0.78-2.58)$ & $1.06(0.58-1.96)$ \\
\hline Psychic autonomy and communication & $0.93(0.57-1.52)$ & $1.19(0.68-2.08)$ & $0.97(0.51-1.83)$ \\
\hline
\end{tabular}

Note: $\$$, No odds ratio could be computed, since none of the people with ischemic heart diseases possessed furnishings; $\$$, No odds ratio could be computed, since none of the people with digestive diseases possessed adaptations to homes; $* \mathrm{p}<0.01,{ }^{*} \mathrm{p}<0.001$. 